DARYL EVANS received his Ph.D. from the University of Colorado. He spent an extended period observing and interviewing mentally retarded people, their parents, and allied professionals. He recently released a film on the issues surrounding a retarded man's movement to a community-based residential setting. In addition to serving as a consultant of federal residential grants, and numerous state service delivery task forces dealing with mental handicaps, he has a book forthcoming on the lives of mentally retarded people. He is currently an Assistant Professor at the University of Kansas with research and teaching interests in medical sociology, mental retardation, and rural health.

ELIZABETH MARET is an Associate Professor at Texas A\&M University. She is active in research on stratification and the sociology of occupations.

VICTOR W. MARSHALL, Associate Professor of Behavioral Science at the University of Toronto, received his Ph.D. in sociology at Princeton. He introduced the first course in the sociology of aging and the first in the sociology of death and dying in a Canadian university. He chairs the Social Sciences Division of the Canadian Association on Gerontology and serves on the editorial boards of The Journal of Gerontology, and Ageing and Society. His publications include over twenty articles and three books, Last Chapters: A Sociology of Aging and Dying, Aging in Canada: Social Perspectives, and Nurses, Patients and Families: Care and Control in the Hospital. A fourth book, Advances in the Social Psychology of Aging and Later Life, will be published in 1982. Professor Marshall's current research focuses on the intergenerational relations of middle-aged and older people and on the socioeconomic implications of population aging.

CLARENCE PARKS is currently a Ph.D. candidate at Texas A\&M University. He received his B.S. from Sam Houston State University in 1969 and his M.A. from Steven F. Austin University in 1976. Clarence is active in teaching research, research on energy, and societal relationships.

\section{AGING IN COMPARATIVE CULTURAL PERSPECTIVE}

\author{
Donald O. Cowgill \\ University of Missouri-Columbia
}

Mid-American Review of Sociology, 1981, Vol. VI, No. 2:1-28

One of man's greatest achievements is the prolongation of life. The average length of life today in modernized societies is approximately three times what it was in primitive societies; we now live about 70 years in contrast with earlier societies in which only about one-half reached maturity and the average length of life was little more than 20 years.

It goes without saying that this lengthening of life expectancy in modern societies eventually results in increased numbers of older people and if in turn those societies also lower their birth rates, thus cutting the numbers and proportions of children, as has happened in all highly modernized societies thus far, the proportion of older people in the population begins to increase.

\section{SELECTED CASES OF AGING}

Figure 1 shows this process in five modernized countries. In 100 years the proportion of the population in France which was 65 and over increased from 7.4 percent to 13.4 percent. In the same period England increased from 4.8 percent to 12.4 percent, Sweden from 5.4 to 13.7 percent and the Netherlands from 5.5 to 10.1 percent. In the last century the proportion of the United States 65 and over has gone up from 2.9 percent to 11 percent.

These cases strongly suggest that the aging of populations is a predictable accompaniment of modernization.

\section{DEGREES OF AGING AROUND THE WORLD}

At the present time we find different parts of the world in different stages of modernization and in consequence in 
Figure 1

Percent 65 and Over in Selected Countries, 1870-1970

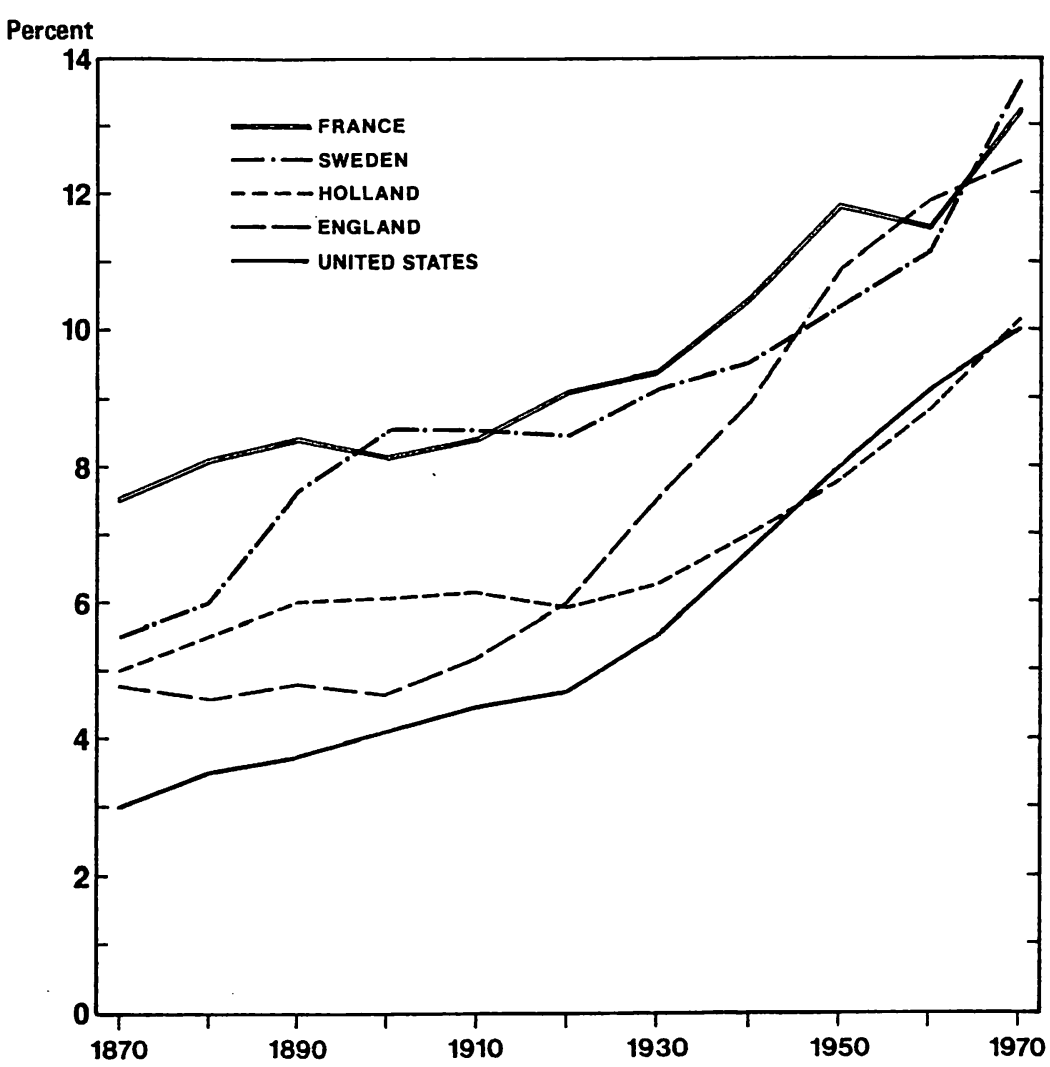

different stages of demographic aging. Figure 2 shows the degree of aging for selected countries.

I describe countries with less than 4 percent of their populations 65 and over as "young populations"; those with 4-6.9 percent as "youthful"; those with 7-9.9 percent as "mature"; and those with 10 percent and over as "aged." Figure 2 shows that many of the countries of Africa, Latin America and Asia are still young; that Japan has now moved into the "mature" category along with Canada, Australia and New Zealand; and that most of the countries of Europe are now "aged." The United States has now climbed over the line and must be called "aged."

In general, Figure 2 supports the principle that demographic aging is proportional to the degree of modernization of the area.

\section{CULTURAL VALUES AND AGING}

Cultural values and modes of treatment of the aged vary at least as widely as demographic statistics. I propose to illustrate this variation by a series of five vignettes of the status and condition of older people in their respective societies-Southeast Africa, Thailand, Russia, Mexico and China.

\section{Southeast Africa ${ }^{1}$}

In southern and eastern Africa the predominant cultural orientation is Bantu. While there are, of course, cultural variations among the local tribes and clans still the whole linguistic group has much in common including their general outlook and philosophy of aging.

Age is not measured in years, it is measured in generations. One becomes old when one's parents and his parents' generation is dead. This really means that one becomes old when he becomes a member of the senior living generation. Given the high mortality of these people this usually happens somewhere between 40 and 50 years of age. 


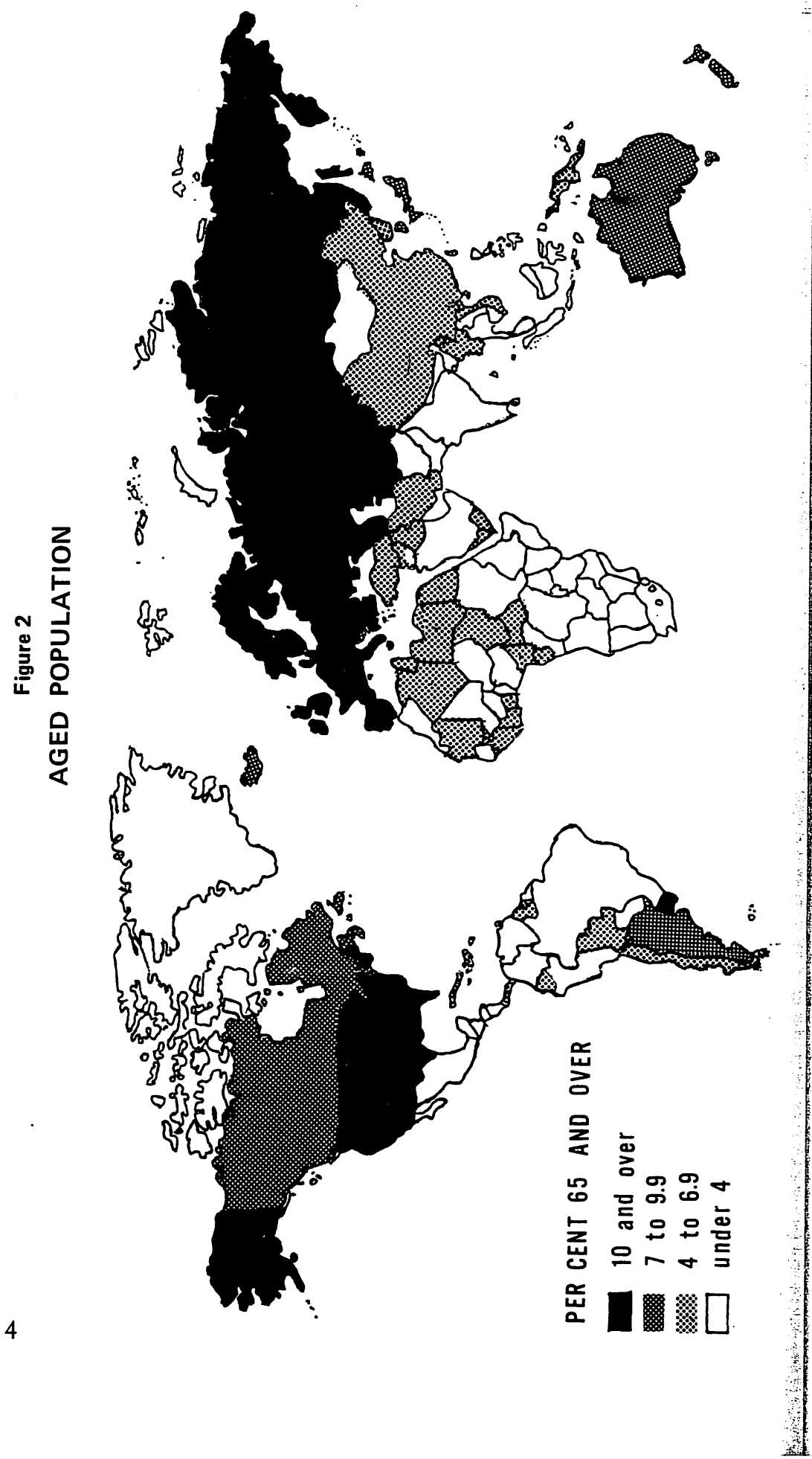

When this happens one moves up a notch in the social ladder; we might say "He has arrived." Old men become headmen of villages, patriarchs of families or clans, or even chiefs of tribes. Older people regardless of their specific position are honored and respected. The headman is known as "Father of the people." Elders have extensive power; they control the land belonging to the sib; they literally control the food supply; they have extensive influence over the marriage arrangements of their sons and daughters.

Thus, older people are the political leaders, the heads of families, the teachers, the seers, the judges and the priests. At meals they are fed first; at ceremonies they are usually the key performers-dancers, singers, and story-tellers. They are the historians of their people, indeed without books or libraries their memories are the repositories of knowledge of their past and the accumulated wisdom of their people.

They are also the closest link with their ancestors. Ancestors are feared and revered. They are believed to have tremendous power for either good or evil; they must be pampered and placated. Old people are the mediators with these powerful spirits and after all, those old people will soon join that spirit world where they too will wield such powers.

\section{Thailand $^{2}$}

I have lived in Thailand for two years; in Chiengmai, 196465 and in Bangkok, 1968-69. Some of the generalizations rest upon personal observation during the normal course of community life, but I have also interviewed many knowledgeable Thais in depth, on the subject of aging and old age. This has been supplemented by systematic interviewing in the village of Ban Khern, a craft village adjacent to Chiengmai. And these observations have, of course, been checked with those of other social scientists who have devoted attention, directly or peripherally, to the subject of old age in Thailand.

The population 65 and over constitutes about 3 percent of the total population of Thailand and only 4.6 percent is over 60 years of age. Even in the old craft village of Ban Khern only 
4 percent of our sample of the general population turned out to be 65 and over, and this ostensibly resulted not from any unusual longevity of the local population, but from some outmigration of the younger generation seeking employment in Chiengmai and Bangkok.

In Thai society, however, old age begins at 60. Age is still computed in twelve-years cycles, and the sixtieth birthday, of course, marks the completion of the fifth cycle. After reaching this venerable age, a person will be addressed by younger persons with special terms of respect, the equivalents of the kinship terms, "grandfather" of "grandmother," even though the speaker may not be related to the older person in any sense of kinship at all. For a person over seventy-two years of age, i.e., one who has completed his sixth cycle, these terms may be preceded by a further term of respect, the whole title meaning "very revered grandfather" or "very revered grandmother." Often special ceremonies constituting rites of passage are held to mark these birthdays and the sons and daughters of such persons seek special ways to commemorate such occasions.

In rural Thailand aging is a very gradual process; there are few abrupt changes or crises and there is certainly no trauma of retirement or old age. In Bangkok, on the other hand, where most people are employees of either government or private corporations and where 60 years of age is still the prevailing age of retirement, there are many signs of discontentment both with such a low retirement age and with the arbitrariness of retirement at any specific age. This is leading to efforts to increase the age for compulsory retirement, particularly for civil servants, and to evasions of it in the form of re-employment in other departments or other industries after being formally retired from another department or industry.

In rural Thailand, the most common pattern of residence for the aged man or woman is to continue to reside in the same household and the same compound which he has occupied since his marriage. Usually one or more of the children will continue to live in the same compound. In northern Thailand, this is usually the youngest daughter. She and her husband will commonly build another house within the same compound, but they remain members of an extended family in the sociological sense, since they are a part of the total group involved in cooking, eating, working, playing, and visiting. The separate houses usually serve only as separate bedrooms in this semi-tropical climate. One-third of all of the households studied in Ban Khern included members of three generations and in all but two of these the second and third generations included a daughter of the older couple and her husband and their children. In several cases there were additional unmarried children of the older couple present and there were a few two-generation households including older people and their unmarried children in their thirties or forties. These resembled the three-generation households in terms of some of their sociological roles-the mutual responsibilities of younger vis-a-vis older generation-although they lacked the in-laws and the grandchildren found in the more extended family groups.

In central Thailand and particularly in Bangkok there is a more varied pattern of residence of the aged. Kaufman, studying a village near Bangkok, found that the prevalent pattern was for the youngest son to continue to reside with his parents and to inherit the land. However, Kaufman also reports one case in which the aged woman rotated her residence among the households of her children.

In all parts of Thailand, regardless of the gender of the children nearest at hand, old people are usually surrounded by some of their children who increasingly assume responsibility for them as they require it. This means that, as yet, the family still provides the basic form of social security for old age. While governmental employees receive small pensions, there is no general system of social security and to date there are only six homes for the aged in all of Thailand and only a thousand residents in all of these.

In the rural areas, even old people who nominally are living by themselves, are in reality, closely surrounded by relatives and friends. Furthermore, the members of the kin group are often brought together in reunions at birthdays, weddings, funerals, and the annual celebration of Songkran, a day specifically devoted to honoring one's elders. Songkran is the traditional Thai 
New Year's Day. Although for the most part the Thais now follow the western calendar, Songkran is still a national holiday which usually falls on the 13th, 14th or 15th of April as the sun enters the astronomical sign of Aries.

In the rural areas, home ownership is almost universal as is ownership of the small patches of land devoted to raising rice, although residences are usually aggregated in villages, while the rice paddies are scattered throughout the countryside. In Ban Khern, 95 percent of the householders owned their homes. Furthermore, a large proportion of all, particularly the aged, have lived in the same community all of their lives. There were only four old people in the sample in Ban Khern who had not been born there and several of these had married into the village some thirty or forty years ago and had lived there ever since. One of these had even learned the Khern language even though it is rapidly dying out now and few of the younger generation can speak it or understand it. As a matter of fact, this old gentleman was one of the best informed of all of the villagers on the history of the Khern people even though he himself was an outsider, having merely married a Khern.

Thai society is very highly stratified. While the social classes are by no means as rigid as in India and there is considerable social mobility within a generation, at any given time one's current status is of utmost importance and must be acknowledged in all social intercourse. The Thai language itself is delicately attuned to the acknowledgement of status both in vocabulary and in tone. Furthermore, age is one of the most important criteria of status and a degree of respect automatically accrues to one who is older than oneself. Thus, it is that in the Thai language one uses different words for older sister (peesao) and for younger sister (nong-sao), for older brother (peechai) and for younger brother (nong-chai). Nor is this kind of distinction limited to one's own generation; an uncle older than one's father is called lung, whereas the father's younger brother is called aar. Similarly, the father's older sister is referred to as par while the younger sister is called nar.

In addition to these linguistic ways of distinguishing age and showing respect for elders, there is an elaborate system of etiquette tending to the same end. From earliest infancy, the child is taught not only the language, but also the gestures and ritual appropriate to persons of different age. An example of this is the subtle variations in the wai depending on the status of the person being addressed. The wai is the Thai gesture of greeting roughly analogous to the the American handshake. It consists of a person placing his hands together, palms touching, in front of him with the fingers pointed upward in what to Westerners appears to be a prayerful attitude. This gesture is usually accompanied by a verbal greeting and often a bowing of the head. A basic element in this etiquette is that the younger person, or the person of inferior status, must always wai first. The level of his hands and the depth of his bow must be carefully calibrated with the status of the person being addressed. One may greet his own contemporaries and equals with a wai with the fingertips at chin level and with only a slight nod, but for an elder or high status person the finger-tips will be a eye level or above and will be accompanied by a deep bow.

In public gatherings, old people have the seats of honor, up in front. In the home, they occupy the honored seats, usually the farthest away from the door. In a parade, the elders lead; at a family meal, they are the first to be fed.

The old Thai custom of crouching in front of one's superiors, including the aged, in order to keep one's head below that of the other person, is dying slowly. King Chulalongkhorn sought to abolish it with reference to royalty nearly a hundred years ago, but while the extreme forms of groveling and crawling have been abated, the milder gestures of deference, including kneeling, bowing and crouching before persons of superior status, including the aged, certainly have not disappeared.

For some of the traditional ceremonies such as the topknotcutting and weddings, the invited guests and participants are the older relatives and friends. For example, only older persons pour lustral water over the hands of the bride and groom at a Thai wedding. An older couple whose marriage has been a happy one is appointed to prepare the nuptial chamber.

But Songkran is the chief ceremony during the year which makes the older persons themselves the stars. The central and 


\section{Mid-American Review of Sociology}

original feature of this festival consisted in the gathering of the younger members of the extended family to pay respects to their elder parents and relatives. They were presented with gifts and with lustral water which they rubbed on their foreheads, temples, and faces, or poured over their heads. These are still the central rituals of the occasion, but in some parts of the country, the holiday has taken on a carnival aspect, one part of which is the indiscriminate dousing of water upon anyone, regardless of age. Since this occurs during the hot, dry season of the year, it may have a certain therapeutic quality.

Age is still a basic determinant of status in Thailand. This is especially true in the rural areas. The villagers of Ban Khern were asked to name the most respected people in the community. Of the eight most frequently named, six were over sixty years of age. Of the two younger persons, one was the abbott at the village wat, who was only 32 , and the other was a 50 -year-old-barber, who was the son of the most prestigious woman of the community, also one of the eight, who was the organizer and proprietor of the only non-cottage type industry, i.e., factory, in the community. Some of her charisma appeared to carry over to her son. But it is important to note that this woman, his mother, was one of the most respected people in the community. This reflects not only the fairly high, and nearly equal, status of women in Thailand in general; it also reflects the heightened status of women in old age when most of their husbands have already died and they remain as the overwhelming majority within their generation.

In spite of this general deference to age, active community leadership passes readily and gracefully into younger hands. Village headmen retire at sixty years of age and, as yet, sixty is the age of compulsory retirement throughout the civil service. As a result, active community leadership is in the hands of the middle-aged. Kingshill found in a community near Chiengmai that of fourteen men attending a particular political meeting the average age was fifty-one, but four were less than fifty. Likewise, we found in Ban Khern that the wat committee, consisting of 16 people, included 11 who were between the ages of 40 and 60 ; only 2 were under 40 and only 3 were over
Aging in Comparative Cultural Perspective

60. One of those under 40 was the head priest at the wat. At present there is little evidence on this point with reference to urban communities in Thailand, but our impression is that in the city where the rule of compulsory retirement is most prevalent and arbitrary, there is increasing resistance to it.

In the rural areas, it is difficult to determine whether an older Thai, particularly a male, would be classified as retired or still employed. Only six of our aged sample in Ban Khern were working away from home, but since many of them had never worked away from home in their entire lives, their work having been carried on at their homes, this is not a good index of employment status. One-third of our sample still identified themselves with a certain occupation and said they were active in it. But, again, in occupations carried on at one's home, in an extended family setting, the pace of work is easily adjusted to the energy and interest of the worker and it is easy to reduce the hours of work per day or to reduce the speed of the labor. One suspects that very often these adjustments occur without the worker or others around him being conscious of it. So in such craft occupations as lacquer-making, silver-smithing, woodcarving, etc., retirement appears to be a very gradual, almost inperceptible, process.

But even those who have retired from their erstwhile lifelong occupations are not usually unoccupied. Older men may no longer plow the rice paddies or flail the rice straws, but they may plant and tend a small vegetable garden and tend the pigs, chickens or water buffalo. They may also "putter" around the compound, repairing the fences and tending the spirit house. Because of their age and wisdom attributed to it, they often also serve as informal advisors and counselors to the younger men of the community.

As in many other societies, there is less discontinuity in the occupational roles of women. It is true of course that those who may have been involved in professional or clerical work may be as arbitrarily retired as their male counterparts, but these are a minute minority of Thai women. Those who have combined craftmanship or culinary skills with salesmanship, may go less frequently to sell their wares in the market. But there are always 
many chores for women about the home, particularly when there are growing grandchildren. Cooking, washing, cleaning, and bathing are necessary repetitive chores at which grandmothers may substitute for younger mothers who may be involved in occupational roles away from home. At the same time, these grandmothers are serving as teachers and disciplinarians. In fact, it appears that it is often the grandmother who is the actual, if unrecognized head of the household, the person who controls much of the daily routine of the members and supervises most of the activities of the children.

In old age in Thailand, both men and women turn increasingly to religious activities. Older women provide food for the priests and clean and care for the wat. The $w a t$ often serves as a social center for the community, but this function is most in evidence for the aged. Many older persons habitually go to the wat daily to visit, to ask counsel and guidance from the priests, and to ask the priests to perform religious ceremonies and chants. Older people are more regular attendants and more active participants in the Wan Phra services. And older women spend much time in preparing for religious festivals. Among the older people in our sample in Ban Khern, one-fourth went to the wat daily and all but two said they went at least once a week.

The increasing amount of time spent at the wat is underscored by the fact that during Buddhist Lent, many older people not only spend their holy days there, but may actually sleep at the wat on the nights preceding and following those holy days.

Furthermore, for some aged men the wat serves as an old folks home. In Buddhism as it is practiced in Thailand, males may enter and leave the priesthood practically as they wish. Traditionally all Thai males were supposed to serve for a period in the priesthood in early adulthood. While this custom is no longer adhered to strictly, there are many men who repair to the wat late in life and serve out the remainder of their days as priests. They, thus, acquire merit, purge themselves of their sins, and are assured of shelter and daily supply of food.

Some of this increasing religiosity appears to be a purposeful preparation for death. In theory, Buddhist are not supposed to fear death; instead they are supposed to look upon it as an escape from the pain and suffering of this life. In Thailand, Buddhism is much inter-mixed with Brahmanism and there is in consequence extensive belief in reincarnation and a tendency to look upon death as an interlude between this life and the next. In this view one's behavior in this life is thought to determine the form of the next life; the more meritorious this life, the higher the form in which one will be reborn. Hence, some of the heightened religious activity of older persons may be viewed as merit-making with the hope of rebirth in a higher form.

Death is an occasion for celebration and merry-making. There is much feasting, gambling and drinking and, at the cremation, gift-giving and fireworks. When the flames have consumed the mortal remains, the watching celebrants can assume that the spirit has escaped and is on its way to a new life, hopefully a better one.

In a society which is undergoing rapid change, it is inevitable that some of the old beliefs, old skills, and old customs should be known only to the older people and be observed only by them. There are numerous illustrations of this principle in Thailand today. Chewing of bettelnut which reddens the lips and blackens the teeth is now seen almost exclusively among older women. Tattooing is most evident among older men. Many of the older women have pierced ears and wear amulets and charms, but this is rare among younger women. While there are class differences as well as generational differences in the forms of dress, older people are much more likely to adhere to the traditional Thai forms of dress, whereas the younger generation is rapidly adopting Western fashions. Likewise, there are generational differences in language; many of the earlier dialects, such as Khern, are now known only to the older generation.

Mexico $^{3}$

In Mexico old age is not defined strictly in terms of chronological years; it is more in terms of one's function-what one does, and who one is in relation to family and community. 
Older people are shown deference, but this does not necessarily mean personal respect. It acknowledges subordination and submission to acknowledged authority; it usually is accompanied with affection; but it does not necessarily imply personal respect.

Most older Mexicans live in three-generation households. Within the household, if not the total extended family, the authority of the oldest male is generally acknowledged. This includes their acknowledgement as heads of households, but it also includes the recognition by children and grandchildren of their right to correct their adult children and over-rule their decisions. In rural Mexico the older male, the graindfather, has and exercises extensive authority in family matters-distribution of property, marriage, and discipline.

There is no retirement in rural Mexico. The older farmer continues to farm to the limit of his physical strength and the older woman continues homemaking responsibilities within her own home and often takes on some supplemental roles related to families of her adult children, both children living in the same household and those living separately but near by. There is extremely high interaction with neighbors and relatives. Children and grandchildren are in and out of the house with great freedom and frequency. In one Mexican village Frances Adams counted three visits per hour by adults-this did not even count the coming and going of the children. There is much mutual aid and service accompanying this interaction-grandmothers babysitting and supervising grandchildren, supplying meals for such grandchildren, often even furnishing a home for them for extended periods, preparing food to be taken to the home of a daughter, etc.

Older people are not active political leaders, primarily because of the modern requirement of literacy, but they are active socially. They are often the leaders and most active participants in the ceremonies and fiestas. Indeed older people are reported to participate with greater freedom and less circumspection than is required of younger people.

In Mexico economic security in old age is still largely a family matter. By custom children are responsible for the support and care of their aged parents and for the most part in rural Mexico this custom is being observed to the extent that family resources can be stretched. The control which the eldest member of the family exercises over the land is a considerable coercive force in meeting this obligation.

Theoretically in this Catholic country there should be an anticipation of rewards in the afterlife, but in real life there is no evidence of this belief. Death is viewed with a fatalistic resignation and is more commonly associated with childhood and infancy than with old age.

\section{Russia $^{4}$}

Grandparenthood seems to be the most significant symbol of elderly status in the U.S.S.R. Workers do retire, but this happens at various ages and retirement is not traumatic and does not carry the stigma that it does in most Western countries. Instead retirement appears really to be accepted as the reward for a life of hard work. Pensions are very modest, but the standard of living already being low they do not entail as much of a reduction as in the U.S.

Older people are respected, but not revered. They usually have a secure place in a household as parents and grandparents. They are welcome and loved, if not pampered, as members of the household; their position being even more welcome since their modest pensions provide a substantial contribution to the household budget. Grandparents are in such demand that a younger couple lacking their own natural parents often adopt an older person or couple. The babushka (grandmother) is a venerated Russian institution. Since during their active years both husband and wife are almost universally employed, the babushka assumes much of the responsibility for homemaking and child care. She does much of the cleaning and cooking as well as the very time-consuming shopping. But grandfather also plays a part in child care-often supervising the children's play in a neighborhood park.

Permissible ages for retirement are 55 for women and 60 for men, but most do not do so until later. Many continue part-time 
employment for many years and some contribute volunteer service to the community.

Leisure time activities are organized for all ages, but especially for those with the most leisure-children and the aged. They are encouraged to attend and participate in the adult education programs and cultural events which are all free of charge.

Much attention is given to health maintenance. There are some 500 health resorts in different parts of the country and older people are among their most frequent clients. While there is much emphasis upon folk medicine in the form of mud baths and mineral waters these spas also provide relaxation and social life. The cost for a month's stay is about $\$ 100$ most of which is paid by the trade union. In the cities there are also what are called "zones of health" which are neighborhood outpatient clinices devoted to preventive maintenance. Many older people go to the clinic every day both for treatment and for sociability.

\section{China}

I went to China three years ago to see if I could detect any erosion of the traditionally high status in which the elderly have been held in that part of the world. There were at least four hypotheses which pointed in the direction of a lower status of the aged in modern China: (1) Modernization, to the extent that it has touched China, should be making inroads upon the status of the aged, (2) Collectivization of the land which was effectively completed in 1958 removed one of the bases of power of older persons-control of land and inheritance rights, (3) Communistic ideology with its emphasis upon egalitarianism, (4) The drive to stamp out Confucianism which had been the major ethical undergirding of the traditional status system, including the ethic of filial piety which required the subordination of the younger generation and assumption of responsibility by the younger generation for support and honor of their elders in their old age.

All four of these changes should have been working in the same direction, leading to the general hypothesis that the relative status of the elderly should be declining in modern China. The main thrust of my observations was to see if I could detect any indications of such a decline of status during such a brief and superficial study tour.

\section{Demographic Aging}

China is already experiencing some aging of its population. The Population Reference Bureau estimates that 6 percent of the population of China is 65 years of age and over (PRB, 1978). This would indicate a still "youthful" population (Cowgill, $1970: 35-38$ ), but one which is farther along in the aging process than most of the developing nations. Prior to the trip to China I had been quite skeptical of the PRB's estimate, but such superficial observations as we could make of their birth control programs pointed consistently toward a lower birth rate than I had previously thought possible. Rough calculations at five points of observation, using the birth and population figures provided by our informants yielded the following crude birth rates: Kwanchow City, 6.6; Changhai Municipality, 7.0; service area of Shanghai Maternity and Children's Hospital, 8.6; Hung Chao Peoples Commune (near Shanghai), 11.0; Nan Yuan Peoples Commune (near Peking), 12.8. Even allowing for the possibility that the figures were adjusted to impress us and acknowledging that the areas observed were urban and suburban these are impressively and consistently low rates. They strengthen the impression that the national birth rate may have decreased more rapidly than most Westerners were aware or willing to admit. The estimate of the Environmental Fund for 1978 was 34 and that of PRB was 26. My observations lead to the belief that the lower figure is closer to reality and that H.Y. Tien's estimate of 20 is certainly possible. If the national birth rate has in fact fallen to the lower 20 s, it is entirely possible that the percent 65 and over may be as high as 6 . I was not able to obtain any direct figures or estimates of such a figure even for local areas.

\section{Living Arrangements}

Nearly all older people are living in family settings. Only 
those with no close living relatives (ascendants, descendants, sibling or affines) are to be found in institutional settings and even many of these individuals live in private family households as the result of a kind of foster home placement. There were 10 such individuals at the Hung Chao Peoples Commune.

The extended family is still very much in evidence. In fact, with declining death rates, it may be more prevalent in fact than in earlier times. Most of the households on which I was able to get information either by observation or interview, included 3 or more generations and many also manifested lateral extension. One, headed by a 69-year old woman, included 14 persons-a married son and wife, an unmarried daughter, 4 grandsons, 3 of whom were married, their wives, and 3 great grandchildren.

Of course, migration forces adjustments in membership of households. Two elderly men in Shanghai were living with grandsons, because, although they had living sons, those sons were living elsewhere. One of our guides who currently makes his home in Peking reported that his parents live with his sister in his native area, Honan Province. This case may illustrate the weakening of the custom of patrilocality of residence, but it does not necessarily indicate any erosion of filial piety, since Mr. Cheng was careful to point out that he sent money to his parents each month.

Homes of Respect

After repeated request we were finally taken to a Home of Respect, this one in the Pu Whang Yu Brigade of the Nan Yuan Commune near Peking. I do not know how many such insitutions exist in China nor what the total inmate population may be, but I am sure that inmate population represents a miniscule proportion of the total aged population. That they exist at all and that they are called "Homes of Respect" reflects the traditional Chinese concern for their elders, even those who are bereft of children or other close relatives. This one housed 70 inmates, including 50 males and 20 females with an average age of 73 , the eldest being 99 . The unusual sex ratio was attributed to the wretched conditions before the Revolution which made it impossible for these men to marry and produce families.
We were not told what happened to the females who might have become their wives under happier conditions.

The Home appeared to provide adequate though not luxurious housing, nutrition and opportunity for activity and socialization. A barefoot doctor operated the health clinic and supervised their health maintenance. We were unable to confirm the availability of bedside nursing. All of the inmates whom we saw were ambulatory even though some gave evidence of arthritis and one old woman had obviously had her feet bound in her childhood.

\section{Retirement and Pensions}

It is consistently stated, usually without qualification, that for manual workers retirement takes place at 55 for males and 50 for females and that non-manual workers retire 5 years later, i.e., 60 for males and 55 for females. However, one quickly discovers that very few people actually retire at these ages. It is true that urban wage workers are permitted to retire on pension at these ages but most workers postpone the event. Some because of their special knowledge or skill are urged to stay on in order to train young apprentices, as in the Silk Embroidery Institute in Soochow. One eminent 82-year old professor was still going strong at East China Teachers University. Thus the announced ages of retirement are by no means mandatory retirement ages; they are more correctly the ages at which some workers become eligible for their pensions if they choose to retire.

But even this applies to less than 20 percent of the workers; it applies only to urban wage and salary workers; it has not yet been extended to the farm workers in the communes, although such an extension is being considered and may be imminent. The amount of the pension now received by retired urban workers appears to be a standard 70 percent of their wages immediately prior to retirement. There is little opportunity for other income after retirement.

\section{Roles and Activities}

Retirement does not mean inactivity, nor any apparent 
Mid-American Review of Sociology

loss of status. Almost all older people are integral members of extended family households in which they continue to play valued and vital roles. Given the fact that younger adult members, of both sexes, are nearly always employed and even in the communes this absents them from the home, older retired members assume heavy responsibility for homemaking and child-rearing. This applies to both sexes. One sees as many grandfathers as grandmothers wheeling or walking young children in the streets. A 63-year old retired textile worker when asked why he had retired the previous June, responded immediately and simply that it was to take care of his grandson. One gets the impression that grandparents may be more continually involved in child-rearing than parents. Older women are also occupied in other aspects of homemaking, including shopping, cooking, mending, etc. On several occasions, I asked who controlled the household expenditures and invariably the older persons were indicated.

But the activities of older people are not confined to the home; they are also involved in neighborhood and community affairs. As noted above, many continue to work well beyond the age of permissive retirement. But, even if retired, most continue to be involved. Volunteering is extensive. A 73-year old retired woodworker was teaching his craft at the Children's Palace in Shanghai in return for a bus ticket. A 63-year old woman proudly displayed on her living room wall a certificate awarded to her for her volunteer service as a Tai Chi instructor. Older people are prominent both as participants and leaders in the ubiquitous early morning Tai Chi exercises. These are obviously social activities as well as physical and mental exercises.

Older people are also involved in other kinds of neighborhood and community social service. Neighborhood primary groups are not only informal social control mechanisms, in China they are systematically used by the courts and Revolutionary Committees to effect compliance with law and local standards.

Older people also organize and participate in the ubiquitous study groups, especially those based in residential areas. Even in the Home of Respect, study groups met three afternoons per week.
Aging in Comparative Cultural Perspective

In China, older people serve the social function of providing historical perspective. It is not so much that they pass on lore and tradition; indeed, their function in this post-revolutionary society is almost the opposite. They are purposefully used to relate stories of pre-revolutionary times in order to show younger Chinese, as well as foreigners, how much conditions have improved. They appear to play this role with sincerity and enthusiasm.

\section{Services for Older People}

As would be expected in a still youthful society in which older people are so well integrated into family and community life, there are few programs or services devoted specifically to older people. They make extensive use of parks, libraries and theaters; they have access to health services, usually without cost. Apparently the only specialized gerontological services are the pensions for retired workers and the Homes of Respect for the few famililess elderly. In 1958 there was a short-lived experiment with home-delivered meals, but in view of the near universal integration of elderly as members of extended family households, it was quickly conceded that such a service on the part of the community was largely unneeded and too costly to be justified by the limited needs served.

\section{AGING AMONG AMERICAN MINORITIES}

While it assists us in gaining perspective on aging to review the condition of older people in other countries, it is also important for us to be sensitive to the variations in aging among subgroups in our own society. There are certainly variations by social class although these have not been extensively researched. Lower class persons have poorer health and lower life expectancy than middle and upper class persons. The former age faster physically and perceive of themselves as old at an earlier age. By contrast, middle class people appear to view old age more negatively and resist being classified as old, perhaps because they have more to lose.

There are also significant variations in aging among our racial and ethnic minorities and there has been a good bit of 
research in this area. Of course Blacks are the major racial minority in our population and some have pointed out that elderly Blacks suffer from "double jeopardy." Their life expectancy is about five years less than whites, they are in poorer health and also perceive themselves to be old at an earlier age. They have lower incomes, more in poverty and are less likely to qualify for private pensions. Mexican-American elderly share the deficits of poverty, limited employability and low education, but in addition are limited by the language barrier which often bars them from knowledge about and access to facilities and resources. Culturally their elders are more ready to accept help from family members, but, by the same token, they are more at a loss when such assistance is not available. Likewise, elderly Chinese-Americans should be able to rely upon filial piety to insure their economic support, but Bengtson finds that those in Los Angeles are seldom actually receiving it. Among all of our minorities, the native American Indians are probably in the direst economic straits. As an ironic testimony to this, we sometimes find that welfare payments serve as a prop to the status of the elderly, since such payments often are the only income to the household and through them the elderly can maintain their status as breadwinners.

\section{MODERNIZATION AND THE STATUS OF THE AGED}

Throughout this paper there has been a recurring theme that the status of the aged is lower in modernized societies and that the status of the aged tends to decline with increase in modernization.

By modernization I mean not just industrialization and not just urbanization but the total transformation of a way of life from a simple rural life dependent upon muscle power with undifferentiated institutions and a traditional outlook to a predominantly urban way of life based upon inanimate sources of energy, highly developed scientific technology, highly differentiated institutions, and a cosmopolitan outlook emphasizing efficiency and progress. There are a number of aspects of modernization which affect the roles and status of older people. Among these, possibly the most salient are: health technology, economic technology, urbanization and education. All of these contribute to the deteriorating status of the aged in modern societies (Figure 3).

\section{Figure 3}

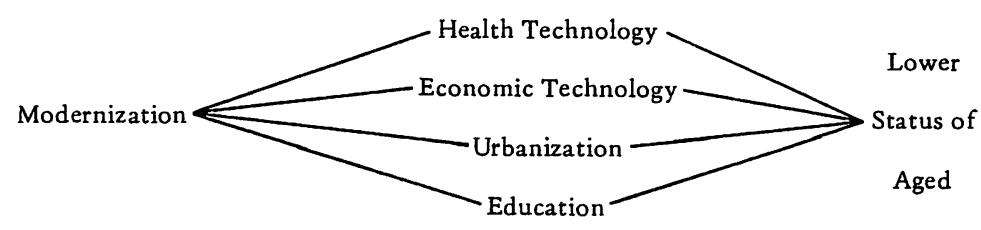

\section{Aging and Health Technology}

Modern health technology is one of the most obvious aspects of modern societies. Here I include under health technology not only the chemical and surgical techniques of modern medicine but the improvements in diet accompanying modernization and all of the repertoire of preventive public health programs such as sanitation and immunization. These are the primary aspects of modernization which account for the prolongation of life and the increase in the numbers of elderly people in the population.

In pre-modern societies people usually continue working until death or incapacity, but since they die early younger workers are always needed to replace them. However, in modern societies as the population ages pressure begins to build as younger people find themselves blocked from jobs or from advancement and eventually this pressure leads to the adoption of the practice of retirement of older workers.

But meanwhile, the process of modernization has led to greater emphasis on work and the job has become the central role in life, the key to one's identity and status in the community. Consequently when one is required to give up his job he loses the chief badge of his identity and the main thing giving 
him status and importance. When this is coupled with a drastic drop in income it is a serious blow to one's ego. Thus modernization in the form of health technology contributes to the undermining of the status of the aged in society.

\section{Aging and Economic Technology}

Under economic technology I include all of the changes usually associated with industrialization and economic development. These encompass: new inanimate sources of power and the application of new inventions to agriculture, industry, transportation and communication. These obviously lead to very profound changes in the way of life: the separation of work from the home, employment in large establishments, new occupations, increasing specialization, increasing scale of operations, large bureaucracies, special interest groups and impersonal relationships.

It is the young workers who go into the new occupations; these often require special training and these new jobs usually pay better and carry more prestige than the older jobs. This is one of the mechanisms which results in children achieving higher status than their parents in modernizing societies. But this reverses the pattern which is usually present in pre-modern societies where older people usually have greater prestige and importance than their children. Thus economic modernization also tends to reduce the status of older people.

\section{Aging and Urbanization}

Urbanization is also a prominent aspect of modernization. A major element of urbanization, especially in the early stages, is extensive migration from rural areas to cities. Furthermore, it is common knowledge that the chief participants in this migration are young people. These migrants leave their parental homes to seek the newly established jobs in the cities; this tends to break up the extended family so characteristic of traditional societies, to separate the younger generation from their parents and kin, to encourage children to establish separate households upon marriage, and to foster the nuclear family as the norm (at the expense of the extended family).

Thus geographic distance comes to separate the generations and this coupled with the social distance arising from the success of the younger generation is rising to higher social status than their parents thus putting a strain on filial bonds. It should not surprise us that the second generation when faced with conflicting demands of aged parents on the one hand and growing children on the other usually give first priority to the needs of their children. And it should be evident that this tendency of the second generation to avoid responsibility for the support of aged parents, a responsibility which was assumed as a matter of course in the extended family, makes it imperative for the society to develop substitute methods of support for the elderly, especially since they are now denied the opportunity of supporting themselves in the labor market. And so modern societies institute pensions and social security to provide economic maintenance of the elderly, even though they always do it on a niggardly scale.

Thus urbanization tends to break up the extended family, separate the generations putting geographic and social barriers between them, isolate the older generation, place it in a precarious and dependent situation, then provide a minimal subsistence administered at the hands of an impersonal bureaucracy. So urbanization too contributes to the downgrading of the elderly.

\section{Aging and Education}

In pre-modern societies most of the population is illiterate. Their knowledge of the past beyond their own personal experience is confined to verbal recitations by other living persons whose experiences transcend theirs. This means that older people are the repositories, the libraries if you will, of knowledge about their past, their traditions, their arts and skills. In such societies older people have a ready-made, essential role to play, a role that is important and carries prestige. 
Mid-American Review of Sociology

Modernization destroys this role and tends to reverse the status relationships. Literacy becomes essential and that is followed by demands for increasing levels of education, but the major educational efforts are invariably directed toward the young. Once the effort has begun the younger generations are always provided with more than their elders. As a matter of fact it often becomes a part of the ideology that children should have greater opportunities than their parents. A consequence of this is that the younger generation is always more highly educated, knows more even about their own past history, than their elders. Elders have been displaced from their former pretigious roles as teachers and seers by libraries, books and schools.

So education as an aspect of modernization also plays its part in undermining the status of the elderly in society, depriving them of an important traditional role and making them inferior to their children in knowledge of their past and present world.

Since its first announcement and elaboration, there has been much research and debate about the validity of modernization theory as related to aging. In the light of all of this new information, I am currently in the process of re-evaluating and restating the theory from my perspective and, in a preliminary way I can say that: (1) The theory as initially expounded was over-simplified; (2) There was and has been a decline in the status of the aged as societies have moved from agrarian-agricultural societies to industrial societies; (3) But this has not been a unilinear change in the wider sweep of history; it is probable that the status of the elders was highest in advanced agricultural societies-higher than in pastoral or hunting and fishing societies; and, (4) It appears probable that as we move into the post-industrial phase, the status and condition of the elderly is rising and will continue to rise. I will present a more elaborate statement of these revisions and qualifications of the theory in the near future.
Aging in Comparative Cultural Perspective

\section{CONCLUSION}

In summary, I have called attention to the worldwide prospect of aging populations. I have noted that because different areas are in different stages of this development, there are presently wide differences in the degree of aging and that the so-called developed countries are now characterized by aged populations, while some of the developing countries of the Third World are still quite young.

I have also noted that there are wide differences in the status and condition of the elderly in different societies. I illustrated this with vignettes from five cultures-Southeastern Africa, Thailand, Mexico, Russia and China. However, I noted that these differences do not occur entirely at random. The status of the aged appears to be correlated with the degree of modernization. Of course, there are other variables that enter into each situation that make the correlation much less than perfect and the theory needs to be modified to take account of these variations in ways that make them more understandable and perhaps predictable. I have also reminded us that these are significant variations in aging by social class and among subcultures within our own society. We need to be sensitive to the different ways in which the elderly are perceived and treated in different cultural settings, both around the world and within our own communities.

\section{FOOTNOTES}

1. Most of the materials on Southeast Africa are drawn from Charles Edward Fuller, "Aging Among Southern African Bantu." Pp. 51-72 in D.O. Cowgill and L.D. Holmes, Aging and Modernization. New York: Appleton-Century-Crofts, 1972.

2. The materials on Thailand are quoted in part from my article "The Social Life of the Aging in Thailand." The Gerontologist 8:(1968): 159-163.

3. The description of aging in Mexico draws heavily upon Frances McAleavey Adams "The Role of Old People in Santo Tomas Mazaltepec." Pp. 103-126 in D.O. Cowgill and L.D. Holmes, Aging and Modernization. New York: Appleton-Century-Crofts, 1972. 
Mid-American Review of Sociology

4. This discussion of aging in the U.S.S.R. is taken in large part from Walter C. McKain, "The Aged in the USSR." Pp. 151-165 in D.O. Cowgill and L.D. Holmes, Aging and Modernization. New York: Appleton-Century-Crofts, 1972

\section{PARTICIPANT OBSERVATION IN A \\ MULTIPLE-METHODS STUDY OF A \\ RETIREMENT COMMUNITY: A RESEARCH NARRATIVE ${ }^{1}$}

\author{
Victor W. Marshall \\ University of Toronto
}

Mid-American Review of Sociology, 1981, Vol. VI, No. 2:29-44

In social science research, choice of methodology is constrained by the real or perceived biases of funding agencies' conception of what will persuade audiences who may or may not use the results of the study for good or evil, and the convictions of investigators as to what constitutes valid data. For most audiences in sociology and social gerontology, and I suspect for most funding agencies, precisely defined and measured variables and numerically tested hypothesis constitute the language of persuasion. As Herbert Blumer (1969:37) argues:

... most research inquiry ... is not designed to develop a close and reasonably full familiarity with the area of life under study. There is no demand on the research scholar to do a lot of free exploration in the area, getting close to the people ... being party to their conversations and watching their life as it flows along. In place of such exploration and flexible pursuit of intimate contact with what is going on, reliance is put on starting with a theory or model, posing a problem in terms of the model, setting a hypothesis with regard to the problem, outlining a mode of inquiry to test that hypothesis, using standardized instruments to get precise data, and so forth....

Blumer suggests that it is difficult to obtain funding for any research that does not conform to the hypothesis-testing model. I sense that this is correct, for the pages of our major sociology and gerontology journals suggest either that it is hard to fund such research or hard to publish it. ${ }^{2}$ 